\title{
Produção Legislativa no primeiro governo Brizola (1983-1987)
}

\author{
Luís Felipe Guedes da Graça ${ }^{1}$
}

\begin{abstract}
RESUMO
Este artigo apresenta a produção legislativa estadual da Assembleia Legislativa do Estado do Rio de Janeiro (ALERJ) durante o primeiro governo de Leonel Brizola (1983-1987). O estudo busca apresentar a relação entre os Poderes Legislativos e Executivos durante um período não estudado anteriormente: o exato momento posterior ao retorno da eleição direta para governadores em 1982. São apresentadas as agendas de cada um dos poderes e a dinâmica de vetos entre eles. Os dados da agenda do Executivo se assemelham aos dos estudos mais recentes nos quais ele aparece como dominando a agenda de assuntos estaduais relevante. A agenda do Legislativo aparece dividida entre leis de pouca relevância e uma agenda social forte. Os dados também mostram que os deputados tinham muito mais dificuldades de enfrentar os vetos do governador em vista das regras mais exigentes para a derrubada desses.
\end{abstract}

Palavras-chave: Política Estadual; Rio de Janeiro; Poder Executivo; Assembleia Legislativa

\begin{abstract}
This paper presents the legislative production approved in the State Legislature of Rio de Janeiro (Alerj) during the first Leonel Brizola's administration (1983-1987). The study introduces the relationship between the Executive and the Legislative branches during a period that was not studied before: The moment just after the return of direct elections for governors in 1982. The data presents the agenda of each branch and the dynamics of vetoes between them. The data of the Executive's agenda resemble more recent studies in which it appears as comprising the States' relevant issues. The Legislative's agenda appears divided between laws of little relevance and a strong social agenda. The data also show that deputies had much more difficulties to face the vetoes of governors in view of stricter rules for the overthrow of these than in recent time.
\end{abstract}

Keywords: State Politics; Executive Power; Rio de Janeiro; State Assembly

\footnotetext{
${ }^{1}$ Mestre em Ciência Política pelo Instituto Universitário de Pesquisa do Rio de Janeiro (IUPERJ). Doutorando em Ciência Política no Instituto de Estudos Sociais e Políticos da Universidade Estadual do Rio de Janeiro (IESP/UERJ). Bolsista da Coordenação de Aperfeiçoamento de Pessoal de Nível Superior (CAPES).1fgraca@ iesp.uerj.br
} 


\section{Introdução}

Os governos estaduais no Brasil têm, pelo menos na atual fase democrática, uma experiência mais antiga de eleições diretas que o governo federal. Em março de 1983 assumiram os primeiros governadores eleitos diretamente desde 1966, ano em que o Ato Institucional $\mathrm{n}^{\mathbf{o}} 3$ definiu que a eleição de governadores deveria ser feita pelos membros das Assembleias Legislativas. Apesar de ter sido um fato pouco lembrado pela mídia neste ano de 2013, os trinta anos de experiência democrática no nível estadual não deixam de ser uma conquista importante.

O caráter federativo do país e o papel desses governadores sempre foram destacados pela literatura de Ciência Política. A eleição ocorrida em novembro de 1982 foi entendida como fundadora de uma dinâmica que viria a se estabelecer na qual os governadores se tornaram importantes atores de veto na política nacional e possuidores de grande capacidade de influência sobre as bases eleitorais de deputados estaduais e federais (Abrucio, 1998).

Esse fato, porém, não serviu de incentivo para que as relações entre Assembleias Legislativas e Executivos estaduais se tornassem objeto frequente dos estudos de Ciência Política. Esse campo, que tem se expandido nos últimos anos (Abrucio, Teixeira e Costa, 2001; Domingues, 2001; Pereira, 2001; Santos, 2001; Grohmann, 2001; Tomio, 2002 e 2005; Tomio e Ricci, 2012; Lopez, 2008, Cervi, 2009), apresenta empecilhos à investigação pela dificuldade em acessar dados das diferentes Assembleias Legislativas e uma tendência de privilegiar o nível federal nas análises. A necessidade de uma coleta mais laboriosa de dados, inclusive por meio da leitura direta do Diário Oficial dos Legislativos Estaduais, impôs, aos pesquisadores que se propuseram à tal empreitada, restringir o número de estados e, principalmente, o número de legislaturas estudadas. Em uma visão geral, os estudos sobre as Assembleias Legislativas se focam em um estado, com recorte temporal curto, geralmente de uma legislatura, não obstante a existência de exceções (Tomio e Ricci, 2012). Outra deficiência do campo tem sido a ênfase em legislaturas mais recentes, com uma lacuna de estudos das relações entre Executivos e Legislativos estaduais da década de 1980 e início dos anos 1990.

Esse foco, da literatura, em legislaturas mais recentes é um problema para o campo porque impede que a hipótese de Abrucio (1998) do "ultrapresidencialismo estadual" seja testada nos diversos estados no período em que o autor defende sua existência. E a escassez de estudos 
com recorte temporal mais alargado, que abranjam diversos governos, dificulta a separação entre o que seriam efeitos das características de governos específicos sobre o padrão da relação entre o Executivo e o Legislativo estadual e os efeitos estruturais que independem dessa variação.

Este artigo busca contribuir para a solução parcial de algumas dessas questões. O que se propõe é analisar os dados da produção legislativa da Assembleia Estadual do Rio de Janeiro (ALERJ) durante o primeiro governo Brizola que durou de 15 de março de 1983 até 15 de março de 1987. Apesar de não apresentar variação de governos, e, portanto, sofrer da mesma deficiência apresentada anteriormente, o recurso à análise do primeiro governo estadual democraticamente eleito do novo Estado do Rio de Janeiro $^{2}$ pode ajudar a entender algumas mudanças e permanências da relação entre a ALERJ e os governadores do estado. Quando possível, lançar-seá mão de dados de outros estudos para permitir uma maior comparabilidade dos dados apresentados.

\section{A eleição do governo Brizola em 1982}

A figura de Brizola na política nacional é fortemente relacionada com os governos Getúlio Vargas e João Goulart, sendo seu retorno do exílio em 1979 um marco do processo de anistia. Seus laços com o Estado da Guanabara, que passou a fazer parte do Estado do Rio de Janeiro em 1975, já eram consideráveis vide a sua votação expressiva ${ }^{3}$ na disputa por um cargo de Deputado Federal em 1962. A vitória da sua candidatura a governador do Estado do Rio de Janeiro era não só um passo de uma ambição pessoal pela possibilidade de posteriormente disputar a Presidência do país (Sento-Sé, 2004), mas também um reflexo de que a eleição de 1982 foi favorável aos opositores do governo militar.

As eleições de 1982 ocorreram com legislação diferente da aprovada na Constituição de 1988. A primeira diferença é que antes da nova Constituição não se adotava no país a instituição do segundo turno. O princípio que regia as eleições para o Executivo estadual e o municipal era o

\footnotetext{
${ }^{2}$ O atual Estado do Rio de Janeiro foi criado em 1975 pela fusão do Estado da Guanabara com o antigo Estado do Rio de Janeiro.

${ }^{3}$ Na eleição de 1962, disputando pelo PTB um cargo de Deputado Federal no Estado da Guanabara, Leonel Brizola recebeu 269.384 votos segundo o site do TSE (BRASIL, 2013). A história política dele, no entanto, se consolidou no Estado do Rio Grande do Sul.
} 
majoritário em turno único. Assim, elegiam-se aqueles candidatos que no pleito alcançassem o maior número de votos, independentemente de terem ultrapassado o patamar de $50 \%$ dos votos válidos. Outra legislação importante que regeu a eleição de 1982 foi a Lei No 6.798/82 que instituiu a obrigação de que o eleitor votasse apenas em candidatos pertencentes ao mesmo partido, para os diferentes cargos, sob pena de nulidade do voto (BRASIL, 1982). Essa lei impedia que o eleitor votasse em um candidato de um partido para deputado federal e de outro partido para governador, por exemplo. Tal medida gerou receio entre os partidos recém-criados, pois obrigava estes últimos a lançar candidaturas para todos os cargos de um distrito. Além desta peculiaridade, a propaganda eleitoral de rádio e televisão era restringida, ainda, pela vigência da Lei Falcão ${ }^{4}$ (BRASIL, 1976).

Mesmo com as restrições mencionadas acima e a perda da sigla histórica do Partido Trabalhista Brasileiro (PTB), ao qual pertenceu durante o período democrático anterior, para Ivete Vargas, Leonel Brizola venceu a eleição de 1982 com mais de 1,7 milhão de votos (34\% dos votos válidos), capitaneando o recém-criado Partido Democrático Trabalhista (PDT). Essa votação, sob a regra dos votos em um só partido rendeu ao primeiro governo Brizola uma bancada de deputados estaduais que representava também 34\% da Casa, contendo 24 deputados estaduais do PDT. Além da vitória no Rio de Janeiro, a oposição ao governo militar venceu em outros nove estados com os candidatos do PMDB, inclusive em estados como São Paulo e Minas Gerais.

A vitória de Brizola foi analisada posteriormente como improvável (Souza, Lima Junior e Figueiredo, 1987), pois o candidato do PDT precisou combater ao mesmo tempo a máquina estadual criada por Chagas Freitas durante os governos eleitos indiretamente e a máquina federal ligada ao governo militar. Este embate ainda tornava-se mais difícil porque Brizola capitaneava um partido ainda em construção, que disputava espaço com o PTB, sigla em que fizera carreira antes do período militar.

Os candidatos que no início da campanha apareceram como principais nomes da disputa foram Sandra Cavalcanti do PTB seguida por Miro Teixeira do PMDB. A primeira tinha história

\footnotetext{
${ }^{4}$ A Lei Falcão fez parte de uma série de medidas tomadas pelo governo militar para diminuir o crescimento da oposição. No caso, a lei censurava a propaganda eleitoral em televisão, limitando à exposição de foto, nome, número e breve currículo do candidato (Souza, 2010).
} 
longa de serviços à União Democrática Nacional (UDN) antes do período militar e havia sido secretária de Estado do governo Carlos Lacerda (1960-1965). Esse histórico tornava sua candidatura pelo PTB, sigla de origem Varguista, uma contradição a ser explorada pelos adversários. Já Miro Teixeira foi o candidato da máquina estadual ligada ao governador Chagas Freitas. ${ }^{5}$ Mesmo pertencendo a uma sigla nacionalmente ligada com a oposição ao governo militar, Miro Teixeira não poderia levantar esta bandeira impunemente porque o MDB fluminense havia controlado o governo estadual durante o período. Além disso, o MDB fluminense havia se especializado em explorar eleitoralmente a política rotineira de apoio às bases locais de cada deputado, estratégia esta que pouco se relacionava com os debates de âmbito nacional em torno do processo de abertura política. Outro candidato que se apresentou foi Moreira Franco pelo Partido Democrático Social (PDS), legenda que seguiu o partido Arena, apoiador do governo militar no Legislativo.

A entrada de Brizola no pleito pela governadoria do Estado significou uma mudança nos termos da disputa e, segundo José Talarico (1998:330) que veio a ser o líder do governo na ALERJ, tinha sua razão na inexistência, até o momento, de um candidato de oposição real. Sandra Cavalcanti e Miro Teixeira buscavam manter a disputa em torno de tema locais, já Brizola pautou sua campanha pela nacionalização dos temas em debate (Sarmento, 2008). Ao conseguir trazer, para horizonte local, a discussão nacional, Brizola conseguiu capitalizar votos tanto daqueles insatisfeitos com o governo militar quanto daqueles insatisfeitos com a dinâmica localista da máquina estadual chaguista. Essa nacionalização da disputa levou, aos primeiros lugares do pleito, o próprio Brizola e Moreira Franco pelo PDS, deixando em terceiro e quarto lugares Miro Teixeira e Sandra Cavalcanti, que eram os favoritos no começo da campanha.

O início do governo Brizola carregou grande expectativa de mudança frente à dinâmica existente da máquina eleitoral criada por Chagas Freitas. Nos termos de Sarmento (2008), o carisma de Brizola conseguiu derrotar a política de rotina da máquina chaguista na eleição. O desafio depois de eleito seria conseguir rotinizar esse carisma no exercício de governo. Esta busca por retirar a política fluminense de uma lógica de interesses paroquialistas aparece no discurso de posse do governador em sua crítica de uma mentalidade partenalista.

\footnotetext{
${ }^{5}$ Para melhor entender a Máquina Chaguista no Rio de Janeiro e como o MDB do estado veio a ocupar o Executivo estadual mesmo durante o governo militar ver Diniz (1982).
} 
Sem me referir às causas e origens da situação em que se encontra o Estado do Rio de Janeiro, todos os Srs. conhecem, desde D. João VI, que sob muitos aspectos ainda se encontra aqui vivendo no Rio de Janeiro, este paternalismo, a marginalização do povo, particularmente do povo trabalhador, enfim um conjunto de situações adversas, que sob muitos aspectos transformou o Rio de Janeiro numa espécie de colônia de nobres; cada setor agindo isoladamente e resolvendo seus problemas; e sempre uma mentalidade paternalista plena, com exclusão da população, seja na articulação e no estudo dos problemas, quanto especialmente nos benefícios das soluções. (Rio de Janeiro, 1983a:06)

Apesar de conseguir emplacar Paulo Ribeiro, um de seus partidários, na Presidência da ALERJ, o governo sofreu dificuldades em angariar apoio da maioria, sendo seus primeiros meses de forte atrito entre os Poderes. Esses atritos decorriam em parte da rejeição do governador em adequar seus atos à lógica da rotinização da política existente no período Chagas Freitas. Esse atrito foi resolvido ao fim do primeiro ano de governo através de um acordo com o PMDB e com o PTB. A indicação, no começo de dezembro de 1983, de alguns deputados estaduais desses partidos a cargos de secretaria de governo selaria o que se poderia chamar de um governo de coalizão.

\section{A teoria sobre Relação Legislativo-Executivo nos Estados e a Produção Legislativa na ALERJ}

A principal tese sobre a relação entre as Assembleias Legislativas e os governadores no Brasil pós-ditadura militar é o livro de Abrucio (1998). Sua proposta é compreendermos a atuação dos governos estaduais como "ultrapresidencialista". Com base em uma visão distributivista da relação entre os deputados estaduais e o Executivo, Abrucio aplica, para dentro dos estados da Federação, a tese de que o sistema eleitoral personalista dá origem a uma dinâmica perversa entre Executivos e Legislativos nos diversos níveis de governo. No caso dos estados, os governadores seriam os "Barões", pois devido à descentralização das competências federativas teriam em suas mãos larga quantidade de recursos fiscais com os quais poderiam construir apoios com a distribuição daqueles. O argumento de Abrucio (1998) se desenvolve durante os anos da abertura política anteriores à Constituição de 1988, porém é com essa que o "ultrapresidencialismo estadual" teria seu ápice e sua consolidação. Como o recorte temporal 
deste artigo (1983-1987) é anterior ao momento em que o autor afirma ter se consolidado esse padrão de relação entre governador e deputados estaduais, é preciso realçar os fatos do período usados pelo autor supracitado como argumento para a formação posterior do “ultrapresidencialismo", sem, no entanto, colocar essa hipótese em teste.

A tese de Abrucio (1998) foi questionada em diversos estudos (Grohman, 2001; Santos, 2001 e Graça, 2012). Tomio e Ricci (2012), ao comparar a produção de diversas Assembleias Legislativas, realçam a ideia de que a dificuldade de formação de uma agenda do Legislativo ligada a assuntos relevantes de políticas públicas não seria apenas resultado da força dos governadores, mas também resultado do caráter concorrente com a União das atribuições do Legislativo estadual, definidas na Constituição de 1988. O ativismo legislativo da União teria tido o efeito de diminuir a agenda de atuação possível dos Legislativos estaduais. Essa hipótese, no entanto, deveria se aplicar apenas aos dados posteriores à Constituição de 1988.

Devido à falta de uma teoria clara sobre o que esperar da relação entre Executivo e Legislativo no período aqui estudado, é preciso realçar as características correntes naquele momento (1983-1987) que tenderiam a aumentar ou diminuir a influência dos governadores de estado sobre as Assembleias Legislativas. Em resumo, essas características seriam: (1) a legitimidade eleitoral, (2) a característica das eleições de 1982 e (3) a descentralização de recursos e a posse de empresas e bancos estaduais.

Primeiramente, há de se destacar que após longo período de veto às eleições diretas para governador e presidente da República pelo governo militar, a eleição de governadores de estado não só tornava estes atores políticos importantes por controlarem máquinas administrativas de grande porte, mas também trazia de volta, ao palco político, atores com agendas sancionadas legitimamente pelo voto e com capacidade de buscar sua implementação. Não é de se estranhar que os governadores da turma de 1982 tenham se tornado líderes nacionais no processo de transição política, tanto no movimento pelo retorno das eleições diretas, quanto na influência sobre o Colégio Eleitoral que elegeu Tancredo Neves em 1985 (Abrucio, 1998).

Em segundo lugar, é preciso realçar o fato de que a legislação eleitoral que estava vigente no momento da eleição de 1982 exigia que os votos nos deputados estaduais fossem dados a candidatos do mesmo partido do candidato escolhido para governador, sob a pena de nulidade do voto. Esta regra cria um efeito coattail entre os cargos. No caso, torna mais direta a possibilidade 
de que candidatos ao Legislativo partidários de um candidato a governador sejam beneficiados pela votação deste. A forte preferência por Brizola para o cargo de governador levou o eleitor a escolher seu candidato a deputado estadual dentre a lista do PDT. Essa legislação mencionada acima parece ser a razão de o governo Brizola ter elegido consigo a maior bancada do partido do governador desde a retomada das eleições diretas para esse cargo em 1982. Este dado é apresentado na Figura 1.

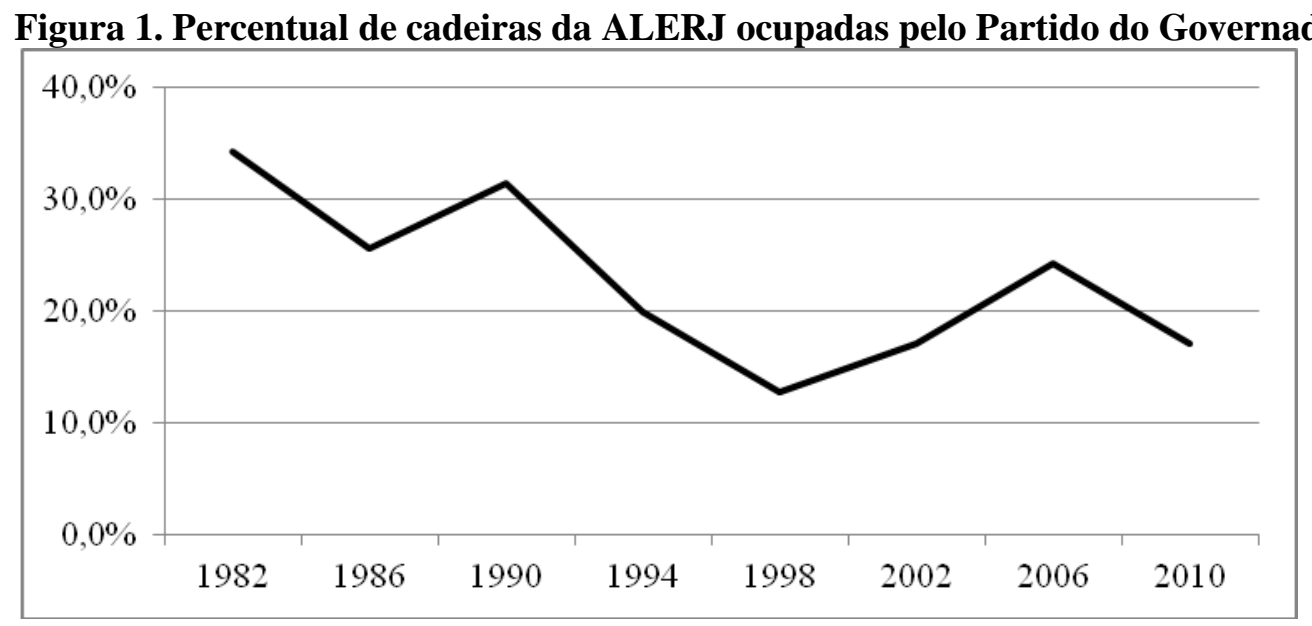

Fonte: Dados do site do TSE.

Por último, e talvez mais importante, os estados brasileiros possuíam em 1982, apesar do período autoritário, capacidade de influência direta sobre políticas públicas e de distribuição de recursos. A capacidade estatal dos entes subnacionais foi ampliada durante o governo militar. Incluso na ideia de desenvolvimento capitaneado pelo estado, após o fim das eleições diretas para governador em 1966, os estados passaram a ser ferramentas do centro de poder. A estratégia de desenvolvimento estatista afetou, inclusive, os estados com a expansão de bancos, universidades e empresas estaduais (Eaton, 2004). Outro ponto importante é que, mesmo antes da retomada das eleições diretas para governadores em 1982, o governo da ditadura militar começou um processo de abertura após as derrotas eleitorais em 1974 que incluíram mudanças nas transferências de receitas para os estados. Os repasses do Fundo de Participação dos Estados (FPE) e do Fundo de Participação dos Munícipios (FPM) foram reforçados a partir de 1975 (Samuels e Abrucio, 2000). 
Estes três fatores podem ser considerados como incentivos para que o governo Brizola tivesse uma relação tranquila com a ALERJ, sendo o principal líder da agenda relevante aprovada e com poucos embates com a Casa. A necessidade do mesmo formar uma coalizão ao fim de 1983 para governar já demonstra que essa expectativa de liderança e tranquilidade na relação não é independente da formação de maioria no Legislativo. Pelo menos, não no caso de um governo que se posicionou como força de esquerda, como o fez Brizola.

A dominância sobre o que é aprovado em um ano legislativo é um indicador que mostra o quanto os projetos vindos de cada Poder compõem do total que é aprovado na Casa legislativa. Não existe um nível de dominância estabelecido como normal. Porém, para o nível federal, o trabalho de Figueiredo e Limongi (1999) mostra uma forte prevalência do Poder Executivo sobre o que é aprovado no Congresso.

No período aqui analisado, o padrão é bem diferente do apresentado na produção legislativa federal desde 1988. Com exceção do breve período de governo Brizola em 1987, ${ }^{6}$ em todos os anos a Assembleia Legislativa teve predominância na autoria das leis aprovadas. Os dados da Tabela 1 mostram que o Poder Executivo teve percentuais de dominância que variaram em torno um quinto e um terço do total no período com um valor extremo de 52,3\% em 1987. Esse valor extremo, nos últimos meses do governo, foi resultado da tentativa de aprovar uma agenda de governo antes do fim do seu mandato, já que, desde o final de 1986, se sabia que o governo seguinte seria ocupado por Moreira Franco do PMDB.

\section{Tabela 1. Percentual de cada Poder da Produção Legislativa}

\begin{tabular}{|c|c|c|c|c|c|c|}
\hline $\begin{array}{l}\text { Leis Ordinárias e } \\
\text { Complementares }\end{array}$ & 1983 & 1984 & 1985 & 1986 & 1987 & $\begin{array}{l}\text { Média do } \\
\text { Governo } \\
\text { Brizola }\end{array}$ \\
\hline Iniciadas pelo Executivo & $\begin{array}{l}31,4 \% \\
(22)\end{array}$ & $\begin{array}{l}27 \% \\
(30)\end{array}$ & $\begin{array}{l}26,1 \% \\
(37)\end{array}$ & $\begin{array}{l}17,8 \% \\
(26)\end{array}$ & $\begin{array}{l}52,3 \% \\
(23)\end{array}$ & $\begin{array}{l}26,9 \% \\
(138)\end{array}$ \\
\hline Iniciadas pelo Legislativo & $\begin{array}{l}68,6 \% \\
(48)\end{array}$ & $\begin{array}{l}71,2 \% \\
(79)\end{array}$ & $\begin{array}{l}70,4 \% \\
(100)\end{array}$ & $\begin{array}{l}80,8 \% \\
(118)\end{array}$ & $\begin{array}{l}47,77 \% \\
(21)\end{array}$ & $\begin{array}{l}71,3 \% \\
(366)\end{array}$ \\
\hline Iniciadas pelo Judiciário & $\begin{array}{l}0 \% \\
(0)\end{array}$ & $\begin{array}{l}1,8 \% \\
(2)\end{array}$ & $\begin{array}{l}3,5 \% \\
(5)\end{array}$ & $\begin{array}{l}1,4 \% \\
(2)\end{array}$ & $\begin{array}{l}0 \% \\
(0)\end{array}$ & $\begin{array}{l}1,8 \% \\
(9)\end{array}$ \\
\hline
\end{tabular}

Fonte: Dados levantados pelo autor com base no Diário Oficial do Legislativo Estadual do Rio de Janeiro. Os números em parênteses são os valores brutos de cada categoria.

\footnotetext{
${ }^{6}$ O governo Brizola durou de 15 de março de 1983 até 15 de março de 1987.
} 
Considerando todo o governo, o Executivo foi responsável por praticamente $27 \%$ das iniciativas que se tornaram leis ordinárias ou complementares. Interessante notar que o Legislativo, definido por teorias posteriores como participante de um pacto homologatório (Abrucio, 1998), foi responsável por mais de 70\% das leis aprovadas no período, chegando a ser responsável por quatro em cada cinco leis aprovadas na ALERJ em 1986. O padrão de predominância do Legislativo era similar ao do período mais recente (Graça, 2012). Esse padrão de maior dominância do Legislativo atual, já presente no governo Brizola, seria similar àquele apresentado no nível federal durante o período 1946-1964 (Tomio e Ricci, 2012).

Outro dado importante referente à relação entre o Poder Executivo e o Poder Legislativo é a taxa de sucesso. Esta última é o percentual de projetos aprovados dentre aqueles que foram enviados pelo governador. ${ }^{7}$ Em todo o período estudado, foram enviadas 163 mensagens ao Legislativo que continham projetos, dessas, 137 viraram lei, o que representa uma taxa de sucesso de 84\%. Tal taxa é um pouco maior que os 78\% (1989-1998) do governo federal em período mais recente (Figueiredo e Limongi, 1999). O fato de 16\% dos projetos iniciados no governo Brizola não terem sido aprovados, todavia, não resultou de derrota do governador no plenário, mas sim de sua ação de retirar as mensagens. Esse dado não deve, porém, esconder a capacidade de alteração nas mensagens pelos deputados estaduais. $\mathrm{O}$ fato de três das mensagens enviadas terem sido aprovadas pela Assembleia, mas vetadas completamente pelo próprio governador, indica que o processo legislativo as alterou de forma a tornar sua sanção custosa.

Para analisar a produção de cada ator de forma mais profunda, foi aplicada uma tipologia taxonômica para separar os assuntos das leis aprovadas em categorias únicas e exclusivas. O uso de tipologias na literatura sobre produção legislativa tem se mostrado profícuo tanto no Brasil quanto na literatura internacional para a análise da agenda de diferentes governos e o teste de hipóteses sobre o paroquialismo dos deputados federais brasileiros (Lapinski, 2008; Santos e Amorim Neto, 2003; Ricci, 2003).

A tipologia consta de dez categorias que buscam abarcar a maior parte da produção legislativa. Essas categorias são apresentadas no Quadro 1. Na coluna de assuntos, há uma lista de temas que são apresentados dentro de cada célula da tipologia. Essa tipologia foi desenvolvida antes do levantamento de dados do período com base em experiência no levantamento da

\footnotetext{
${ }^{7}$ Considero aqui tanto projetos de lei ordinária, projetos de lei complementar e emendas constitucionais.
} 
produção legislativa da ALERJ de outros períodos. Foi escolhido criar categorias para leis de declaração de utilidade pública e de caráter honorífico para destacá-las dos outros tipos devido a sua recorrente incidência na produção e por serem descritas como leis de pouco impacto ou de pouca importância (Abrucio, Teixeira e Costa, 2001).

\section{Quadro 1. Tipologia Taxonômica de classificação legislativa por assunto}

\section{Tipologia Taxonômica Assunto

\begin{tabular}{l|lll} 
Administrativo & $\begin{array}{l}\text { Estrutura Administrativa, Processo } \\
\text { Adequação de Leis e outros }\end{array}$ & Administrativo, Pessoal, Previdência, \\
\hline $\begin{array}{l}\text { Desenvolvimento Cultural e } \\
\text { Tecnológico }\end{array}$ & $\begin{array}{l}\text { Cultural, Científico e Tecnológico } \\
\text { (n) }\end{array}$ &
\end{tabular}

Declaração de Utilidade Pública

Econômico

Honorífico

Orçamentário

Segurança

Social
Projetos que declaram entidades da sociedade civil como sendo de utilidade pública estadual

Incentivos Fiscais, Autorização de Empréstimos, Infraestrutura, Fiscalização, Arrecadação, Piso Salarial, Tributos, Adequação de Leis e outros Instituição de datas comemorativas e outros Projetos orçamentários ou de crédito especial

Tamanho da corporação, Piso Salarial, Melhorias técnicas e de armamento, Treinamento e outros

Direitos das Minorias, Idosos, Deficientes Físicos, Utilidade Pública, Saúde, Educação, Assistência Social, Drogadição, Direitos do Consumidor e outros

Meio Ambiente $\quad$ Projetos de proteção ao Meio Ambiente

Outros

Projetos de leis que não se encaixam em nenhum dos temas acima

\section{Agenda do Executivo}

Os dados da agenda do Executivo são apresentados na Tabela 2 abaixo. A agenda do Executivo apresenta uma constante: a predominância de projetos de caráter administrativo. Esses projetos somam, em todo o período, mais da metade das leis aprovadas na ALERJ e iniciadas pelo governador. Nos últimos meses de governo, no início do ano de 1987, elas chegaram a representar mais de $80 \%$ da produção. É interessante notar que a necessidade de reformar a estrutura administrativa apareceu de forma recorrente nas mensagens de início de ano enviadas pelo governador à ALERJ e foi enfrentada pela reformulação do quadro de diversos órgãos da administração direta do estado. Na mensagem lida em plenário no dia 23 de setembro de 1983, 
pela comemoração dos seis meses de governo (Rio de Janeiro, 1983b), ressaltou-se o combate ao "entreguismo", principalmente pela crítica à gestão de seu antecessor por ter feito uma série de nomeações para cargos públicos de forma irregular e que buscavam influenciar a eleição anterior. A crítica à estrutura administrativa herdada do governo Chagas Freitas, assim como da dificuldade de relação com o governo federal, tanto no período militar quanto no governo Sarney, permeiam todas as mensagens enviadas pelo governador aos deputados estaduais.

A segunda categoria que mais recebeu projetos foi a área de Segurança. O conteúdo desses projetos de lei modificava o piso salarial dos policiais e bombeiros, fixava seus efetivos e alterava regras internas da corporação, tratando da questão da ascensão da carreira e dos cursos formadores. A atenção a esta temática tem uma variação grande no período, mas esteve presente em $16,7 \%$ da produção com origem no Palácio Guanabara. É propício lembrar que a questão da Segurança foi um ponto de crítica forte ao governo Brizola. $\mathrm{O}$ combate à criminalidade não necessitava de projetos de lei, mas tanto as reformas das estruturas da corporação quanto a expansão do efetivo precisavam passar pela aprovação da ALERJ. No campo do discurso, o governador ressaltava a implantação de uma política de Segurança que visasse o respeito aos direitos humanos com a proibição da entrada de policiais em favelas "arrombando barracos" (Rio de Janeiro, 1983b:13) e a repressão aos grupos de extermínio que atuavam na baixada fluminense. A relevância alcançada por essa área na atuação do governo mostra que, apesar das críticas sofridas, existia uma agenda de segurança no estado, focada, porém, na reformulação da estrutura policial.

Tabela 2. Produção legislativa iniciada pelo Poder Executivo por Assunto

\begin{tabular}{|l|l|l|l|l|l|l|}
\hline & 1983 & 1984 & 1985 & 1986 & 1987 & $\begin{array}{l}\text { Governo } \\
\text { Brizola }\end{array}$ \\
\hline Administrativo & $54,5 \%$ & $53,3 \%$ & $54,1 \%$ & $53,8 \%$ & $87 \%$ & $59,4 \%$ \\
& $(12)$ & $(16)$ & $(20)$ & $(14)$ & $(20)$ & $(82)$ \\
\hline Econômico & $13,6 \%$ & $20 \%$ & $13,5 \%$ & $3,8 \%$ & $0 \%$ & $10,9 \%$ \\
& $(3)$ & $(6)$ & $(5)$ & $(1)$ & $(0)$ & $(14)$ \\
\hline Orçamentário & $9,1 \%$ & $6,7 \%$ & $16,2 \%$ & $11,5 \%$ & $0 \%$ & $9,4 \%$ \\
& $(2)$ & $(2)$ & $(6)$ & $(3)$ & $(0)$ & $(14)$ \\
\hline Segurança & $18,2 \%$ & $16,7 \%$ & $10,8 \%$ & $30,8 \%$ & $8,7 \%$ & $16,7 \%$ \\
& $(4)$ & $(5)$ & $(4)$ & $(8)$ & $(2)$ & $(23)$ \\
\hline Social & $0 \%$ & $3,3 \%$ & $0 \%$ & $0 \%$ & $0 \%$ & $0,7 \%$ \\
& $(0)$ & $(1)$ & $(0)$ & $(0)$ & $(0)$ & $(1)$ \\
\hline Meio Ambiente & $0 \%$ & $0 \%$ & $0 \%$ & $0 \%$ & $4,3 \%$ & $0,7 \%$ \\
& $(0)$ & $(0)$ & $(0)$ & $(0)$ & $(1)$ & $(1)$ \\
\hline
\end{tabular}




\begin{tabular}{|l|l|l|l|l|l|l|}
\hline Outros & $\begin{array}{l}4,5 \% \\
(1)\end{array}$ & $\begin{array}{l}0 \% \\
(0)\end{array}$ & $\begin{array}{l}5,4 \% \\
(2)\end{array}$ & $\begin{array}{l}0 \% \\
(0)\end{array}$ & $\begin{array}{l}0 \% \\
(0)\end{array}$ & $\begin{array}{l}2,2 \% \\
(3)\end{array}$ \\
\hline Total & $100 \%$ & $100 \%$ & $100 \%$ & $100 \%$ & $100 \%$ & $100 \%$ \\
& $(22)$ & $(30)$ & $(37)$ & $(26)$ & $(23)$ & $(138)$ \\
\hline
\end{tabular}

Fonte: Dados levantados pelo autor com base no Diário Oficial do Legislativo Estadual do Rio de Janeiro. Os números em parênteses são os valores brutos de cada categoria.

O terceiro assunto que mais dominou a agenda legislativa do governo estadual foram as leis de caráter econômico. Apesar das leis orçamentárias apresentarem a mesma proporção da produção legislativa, estas últimas são de caráter restrito aos orçamentos anuais e pedidos de crédito suplementar. As leis aprovadas da área econômica englobaram principalmente mudanças na legislação tributária do estado e autorizações de empréstimos. A mais importante lei desse campo, e uma das mais importantes do primeiro governo Brizola, foi a Lei 713 de 1983 que criou as regras de distribuição de parte do $\mathrm{ICM}^{8}{ }^{8}$ afetando diretamente a arrecadação dos munícipios. A área econômica, pelas ações legislativas e administrativas do governo, acabou sendo pauta central das mensagens enviadas pelo governador à ALERJ, dada a crise econômica que o país atravessava no início dos anos 1980 e a dificuldade encontrada pelo governador em ter verbas de empréstimos e mesmo de repasses constitucionais liberados pelo governo central. A dificuldade de arrecadação levou, inclusive, o governador a buscar a aprovação de uma lei que permitia o pagamento de créditos tributários do ICM através de bens e imóveis. ${ }^{9}$

As categorias taxonômicas Social, Meio Ambiente e Outros tiveram papel residual na agenda legislativa do Executivo estadual neste período. Juntas elas respondiam por menos de 5\% das leis aprovadas com origem no Palácio Guanabara. Isto não significa que o governo Brizola não teve uma atuação social destacada. Um dos projetos sociais mais festejados do governo, a implantação dos Centros Integrados de Educação Pública (CIEPs), não necessitou de um projeto de lei estadual para sair do papel. Assim como a implantação de passe livre para os estudantes uniformizados, outra medida de caráter social importante. Os governadores têm até hoje liberdade de atuação em diversas áreas através da utilização de seus decretos executivos e das

\footnotetext{
${ }^{8}$ O ICM - Imposto sobre Circulação de Mercadoria - é o antecessor do que hoje é o ICMS - Imposto sobre Operações relativas à Circulação de Mercadorias e Prestação de Serviços de Transporte Interestadual e Intermunicipal e de Comunicação.

${ }^{9}$ Lei 688 de 1983, resultado do projeto de lei 156/83 que constou da mensagem de número 09 do mesmo ano.
} 
portarias das secretárias estaduais. O caminho legislativo não necessita ser trilhado quando a estrutura legal permite ao governador atuar em certas áreas. ${ }^{10}$

O padrão da agenda do Executivo não se distingue fortemente daquela apresentada por estudos posteriores. O governador pautou sua agenda por temas administrativos, econômicos e de reforma da estrutura da força policial. Leis que reajustavam salários de categorias de servidores ou estruturavam carreiras do Estado dominaram a agenda administrativa do governo. O caráter ainda recente da Fusão do Estado da Guanabara com o Estado do Rio de Janeiro pode ser uma das explicações para tal predominância. A alta inflação no período também ajuda a explicar a necessidade de reajustar salários que se desatualizaram com o passar do tempo. Já a agenda econômica do governo se pautou mais por reformas no ICM, algumas autorizações de empréstimos e a tentativa de assegurar, ao Estado, a solvência de sua máquina administrativa. A crise administrativa do Estado era clara quando o governador deixou patente que a estrutura administrativa recebida no momento da posse gerava gastos anuais maiores que a receita líquida do ICM. Para diminuir esse déficit, uma das mais importantes leis de caráter econômico criou o Imposto sobre a Propriedade de Veículos Automotores (IPVA) no Estado.

É interessante ressaltar algo que é característico das constituições estaduais anteriores à Constituição Federal de 1988, principalmente a do Estado do Rio de Janeiro que foi promulgada após a fusão dos Estados da Guanabara e do antigo Estado do Rio de Janeiro em 1975, em pleno governo militar. Essa Constituição previa dois mecanismos que serviam para fortalecer o governador frente à Assembleia. Um referente aos vetos e um referente aos projetos de lei com pedido de urgência. O primeiro deles, cujo efeito será apresentado em breve, previa que os vetos precisariam ser votados em 45 dias ou seriam considerados mantidos por decurso de prazo. ${ }^{11} \mathrm{O}$ segundo, ainda mais importante para a agenda do governador, estabelecia que o governador poderia solicitar a urgência de projetos de maneira que fossem votados em 40 dias e, caso este prazo se esgotasse, esses projetos seriam colocados como primeiros da pauta da ordem do dia, em dias sucessivos. Por sua vez, se, mesmo sob esta regra, os projetos não fossem apreciados, eles

\footnotetext{
${ }^{10}$ Este fato não é uma característica apenas dos governos anteriores à Constituição de 1988. Um dos maiores exemplos atuais de mudança de política pública sem necessidade de alteração legal ou autorização do Legislativo são as Unidades de Polícia Pacificadoras (UPPs) do Estado do Rio de Janeiro criadas através de decreto estadual.

${ }^{11} \S 4$ do artigo 45 da Constituição do Estado (Rio de Janeiro, 1975).
} 
seriam considerados definitivamente aprovados. ${ }^{12}$ Após a derrota de seu candidato à sucessão nas eleições de 1986, o governo Brizola convocou sessões extraordinárias entre os dias 21 de dezembro de 1986 e 30 de janeiro de 1987, as quais foram em maioria derrubadas por falta de quórum, impedindo a votação das matérias em pauta. Mesmo assim, fazendo uso do pedido de urgência, o governo teve aprovados 23 projetos de lei de sua iniciativa no ano de 1987.

\section{Agenda do Legislativo}

O Legislativo foi responsável por mais de dois terços das leis aprovadas no período, mas ainda não é conhecida a agenda dos deputados estaduais. Que tipos de leis foram aprovadas? Para responder essa questão, aplicou-se a mesma tipologia taxonômica anterior às leis com origem no Legislativo. O resultado é apresentado na Tabela 3.

Tabela 3. Produção legislativa iniciada pelo Poder Legislativo por Assunto

\begin{tabular}{|c|c|c|c|c|c|c|}
\hline Agenda do Legislativo & 1983 & 1984 & 1985 & 1986 & 1987 & Total \\
\hline Administrativo & $\begin{array}{l}29,2 \% \\
(14)\end{array}$ & $\begin{array}{l}11,4 \% \\
(9)\end{array}$ & $\begin{array}{l}16 \% \\
(16)\end{array}$ & $\begin{array}{l}22,9 \% \\
(27)\end{array}$ & $\begin{array}{l}19 \% \\
(4)\end{array}$ & $\begin{array}{l}19,1 \% \\
(70)\end{array}$ \\
\hline Declaração de Utilidade Pública & $\begin{array}{l}29,2 \% \\
(14)\end{array}$ & $\begin{array}{l}34,2 \% \\
(27)\end{array}$ & $\begin{array}{l}29 \% \\
(29)\end{array}$ & $\begin{array}{l}24,6 \% \\
(29)\end{array}$ & $\begin{array}{l}28,6 \% \\
(6)\end{array}$ & $\begin{array}{l}28,7 \% \\
(105)\end{array}$ \\
\hline $\begin{array}{l}\text { Desenvolvimento Científico e } \\
\text { Tecnológico }\end{array}$ & $\begin{array}{l}4,2 \% \\
(2)\end{array}$ & $\begin{array}{l}0,0 \% \\
(0)\end{array}$ & $\begin{array}{l}2 \% \\
(2)\end{array}$ & $\begin{array}{l}0,8 \% \\
(1)\end{array}$ & $\begin{array}{l}0,0 \% \\
(0)\end{array}$ & $\begin{array}{l}1,4 \% \\
(5)\end{array}$ \\
\hline Econômico & $\begin{array}{l}0,0 \% \\
(0)\end{array}$ & $\begin{array}{l}0,0 \% \\
(0)\end{array}$ & $\begin{array}{l}0 \% \\
(0)\end{array}$ & $\begin{array}{l}0,8 \% \\
\text { (1) }\end{array}$ & $\begin{array}{l}0,0 \% \\
(0)\end{array}$ & $\begin{array}{l}0,3 \% \\
(1)\end{array}$ \\
\hline Honorífico & $\begin{array}{l}10,4 \% \\
(5)\end{array}$ & $\begin{array}{l}30,4 \% \\
(24)\end{array}$ & $\begin{array}{l}26 \% \\
(26)\end{array}$ & $\begin{array}{l}26,3 \% \\
(31)\end{array}$ & $\begin{array}{l}4,8 \% \\
(1)\end{array}$ & $\begin{array}{l}23,8 \% \\
(87)\end{array}$ \\
\hline Meio Ambiente & $\begin{array}{l}4,2 \% \\
(2)\end{array}$ & $\begin{array}{l}6,3 \% \\
(5)\end{array}$ & $\begin{array}{r}3 \% \\
(3)\end{array}$ & $\begin{array}{l}4,2 \% \\
(5)\end{array}$ & $\begin{array}{l}4,8 \% \\
\text { (1) }\end{array}$ & $\begin{array}{l}4,4 \% \\
(16)\end{array}$ \\
\hline Segurança & $\begin{array}{l}2,1 \% \\
(1)\end{array}$ & $\begin{array}{l}1,3 \% \\
(1)\end{array}$ & $\begin{array}{l}0 \% \\
(0)\end{array}$ & $\begin{array}{l}0,8 \% \\
(1)\end{array}$ & $\begin{array}{l}0,0 \% \\
(0)\end{array}$ & $\begin{array}{l}0,8 \% \\
(3)\end{array}$ \\
\hline Social & $\begin{array}{l}12,5 \% \\
(6)\end{array}$ & $\begin{array}{l}11,4 \% \\
(9)\end{array}$ & $\begin{array}{l}23 \% \\
(23)\end{array}$ & $\begin{array}{l}18,6 \% \\
(22)\end{array}$ & $\begin{array}{l}38,1 \% \\
(8)\end{array}$ & $\begin{array}{l}18,6 \% \\
(68)\end{array}$ \\
\hline Outros & $\begin{array}{l}8,3 \% \\
(4)\end{array}$ & $\begin{array}{l}5,1 \% \\
(4)\end{array}$ & $\begin{array}{l}1 \% \\
(1)\end{array}$ & $\begin{array}{l}0,8 \% \\
(1)\end{array}$ & $4,8 \%(1)$ & $\begin{array}{l}3 \% \\
(11)\end{array}$ \\
\hline Total & $\begin{array}{l}48 \\
(100 \%)\end{array}$ & $\begin{array}{l}79 \\
(100 \%)\end{array}$ & $\begin{array}{l}100 \\
(100 \%)\end{array}$ & $\begin{array}{l}118 \\
(100 \%)\end{array}$ & $\begin{array}{l}21 \\
(100 \%)\end{array}$ & $\begin{array}{l}366 \\
(100 \%)\end{array}$ \\
\hline
\end{tabular}

Fonte: Dados levantados pelo autor com base no Diário Oficial do Legislativo Estadual do Rio de Janeiro. Os números em parênteses são os valores brutos de cada categoria.

\footnotetext{
${ }^{12} \S 3$ do artigo 41 da Constituição do Estado (Rio de Janeiro, 1975).
} 
Os dados da Tabela 3 contrastam diretamente com os da Tabela 2, da produção derivada do Executivo. O Legislativo estadual pautou sua agenda principalmente por medidas que declaravam uma entidade como sendo de utilidade pública $(28,7 \%)$ ou que tinham algum caráter honorífico $(23,8 \%)$. Somadas, estas categorias representavam mais da metade das leis aprovadas na ALERJ com origem no Legislativo. Este padrão não é destoante daquele de tempos mais recentes no Estado do Rio de Janeiro (Graça, 2012) e nem de outros Estados (Tomio e Ricci, 2012). A tendência das Assembleias produzirem uma quantidade considerável de leis que têm pouco impacto real e afetam poucas pessoas é parte da razão de, muitas vezes, se considerar a prevalência de um pacto homologatório entre a Assembleia e o governador (Abrucio, 1998) onde este último é o responsável pela agenda mais relevante.

No entanto, definir o caráter da agenda legislativa dos deputados estaduais como pouco expressiva, com base apenas na quantidade de projetos de declaração de utilidade pública e de caráter honorífico, mais obscurece que clarifica a análise. Esses projetos têm maior incidência devido a sua maior facilidade de aprovação e por terem uma tramitação mais célere que os outros (Graça, 2012).

Outro ponto importante é que há de se esperar do governador uma predominância na agenda relevante já que ele é um ator unitário e que foi eleito tendo essa como discurso. A legitimidade eleitoral da agenda executiva vencedora de um pleito popular é grande. Considerando o fato de que o governador é um ator unitário e a Assembleia uma junção de atores múltiplos e com visões, muitas vezes, opostas, não é de se estranhar que exista uma tendência de o governador liderar a agenda estadual relevante. Isto, no entanto, não é suficiente para atestar a fraqueza da Assembleia como corpo legislativo.

Os dados mostram que as categorias Administrativo e Social tiveram incidência frequente, com cada uma delas alcançando quase $20 \%$ do total da produção legislativa dos deputados estaduais. A produção classificada como Administrativo inclui agenda importante como a criação de regras para a implantação de usinas nucleares ${ }^{13}$ e a criação de um tribunal do imposto. ${ }^{14}$ Já a categoria Social inclui temas dos mais diversos, com legislação focada em Educação, Saúde, Direitos das Pessoas com Deficiência, Assistência Social, Utilidade Pública, entre outros. Estas

\footnotetext{
${ }^{13}$ Lei 785 de 1984.

${ }^{14}$ Lei 770 de 1984.
} 
leis incluem algumas de maior impacto, exemplificado pela criação de um sistema estadual de creches, ${ }^{15}$ pela permissão para a realização de abortos em situações de perigo à vida da mãe ou de gravidez decorrente de estupro ${ }^{16}$ e pela obrigatoriedade de a Assistência Judiciária manter defensores públicos nos estabelecimentos penais sob administração do estado para atendimento permanente aos presos e internados juridicamente necessitados. ${ }^{17}$ Desconsiderar a importância dessas leis por elas dividirem a agenda do Legislativo com decisões de menos impacto importaria na perda de capacidade de análise que estudos de uma legislatura, como este, não deveriam incorrer.

Descontando as legislações de declaração de utilidade pública e de caráter honorífico, a agenda do Legislativo continua tendo sido maior que a do Executivo. Enquanto o governador aprovou 138 atos legais, a Assembleia, com o desconto citado, foi responsável por 174 leis. Embora o desconto dessa legislação pouco relevante ajude a surgir um padrão mais paritário de iniciativa de lei entre os poderes que o apresentado na Seção 2, o Poder Legislativo continuou sendo dominante, com 54,2\% do total de leis, enquanto o Executivo passou a ser responsável por $42,9 \%{ }^{18}$

\section{Vetos}

Uma forma mais aberta de divergência entre os Poderes Legislativo e Executivo são os momentos em que os dois apresentam discordância sobre o resultado de um projeto legislativo. Quando a Assembleia aprova um projeto de lei, ela o envia para o governador e ele pode assinar, tornando-o lei, ou pode devolvê-lo para a Assembleia com veto parcial ou total, acompanhado de um texto que apresente as razões do veto. Uma vez que um projeto de lei seja vetado, cabe à Assembleia decidir se derruba ou mantém o veto imposto pelo governador. A Tabela 4 apresenta os dados referentes aos vetos apostos no período.

\footnotetext{
${ }^{15}$ Lei 837 de 1985.

${ }^{16}$ Lei 832 de 1985.

${ }^{17}$ Lei Complementar 49 de 1986.

${ }^{18} \mathrm{O}$ que falta para completar $100 \%$ são os 2,8\% referentes ao Poder Judiciário.
} 
Tabela 4: Vetos Parciais e Totais apostos pelo governador

\begin{tabular}{|c|c|c|c|c|c|c|}
\hline & 1983 & 1984 & 1985 & 1986 & 1987 & $\begin{array}{l}\text { Governo Brizola } \\
\text { (Soma) }\end{array}$ \\
\hline Vetos Parciais & 14 & 11 & 17 & 15 & 0 & 57 \\
\hline Vetos Totais & 15 & 13 & 14 & 44 & 0 & 86 \\
\hline Soma & 26 & 24 & 31 & 59 & 0 & 143 \\
\hline
\end{tabular}

Fonte: Dados levantados pelo autor com base no Diário Oficial do Legislativo Estadual do Rio de Janeiro.

Os dados indicam que o governador remeteu durante seu mandato uma quantidade considerável de razões de veto para a Assembleia. O padrão do número de vetos por ano foi de 25 a 30 vetos, com exceção do ano de 1986, no qual o governador devolveu 59 projetos de lei aprovados na ALERJ com vetos apostos, e do ano de 1987, no qual o governador não emitiu vetos durante os três meses de gestão. Os dados também indicam que, nos primeiros três anos de governo, o governador não apresentava tendência a apor mais vetos de qualquer um dos tipos (totais ou parciais). A partir de 1986, os vetos totais alcançaram um patamar acima do dobro dos vetos parciais. Fato este que parece indicar maior conflito entre os dois poderes.

Os dados apresentam uma dinâmica de vetos menos intensa que no período recente (Graça, 2012): o ano de 1986, com a maior incidência, teve pouco mais vetos que o ano de 2010, cujos vetos somaram 52 representando a menor divergência dos poderes entre 2003 e 2010. ${ }^{19}$ Por sua vez, a predominância de vetos totais é similar ao período mais recente.

Apesar da aposição de uma quantidade considerável de vetos, poucos foram derrubados. O ano de 1986 apresenta as únicas quatro derrubadas de veto, sendo dois parciais e dois totais. Este dado contrasta fortemente com o período mais recente. Neste, apesar da grande quantidade de vetos apostos, os deputados estaduais têm demonstrado intensa disposição para manter suas decisões e capacidade de ação coletiva para isto. No período recente, a taxa de derrubada de vetos apostos passa dos 36\% (Graça, 2012). A discrepância entre os dois períodos é decorrente, em parte, do fato de que, antes da Constituição Estadual promulgada em1989, o processo legislativo dos vetos não obrigava a ocorrência de uma votação sobre a manutenção ou derrubada deste. Caso a Assembleia não decidisse sobre o veto em 45 dias, este seria dado como mantido por

\footnotetext{
${ }^{19}$ O período de 2003 a 2010 conteve dois governos. O da governadora Rosinha Garotinho (2003-2006) e o primeiro governo de Sérgio Cabral (2007-2010).
} 
decurso de prazo. Tal foi o resultado de 38 vetos apostos pelo governador. As maiorias necessárias para derrubar um veto também eram diferentes, pois, até 1989, eram necessários os votos de dois terços dos deputados, ${ }^{20}$ enquanto, nas novas regras, são necessários os votos da metade dos deputados estaduais.

Os dados indicam que existiu um embate entre Legislativo e Executivo, apesar de menor que aquele que ocorre no período mais recente. Neste conflito, durante o governo Brizola, os deputados apresentaram pouca capacidade de bancar suas decisões, tendo derrubado uma quantidade pequena de vetos frente ao total aposto. Esta dificuldade decorreu da exigência de um número expressivo de votos para a derrubada de vetos e do fato de o partido do governador possuir uma bancada grande o bastante para bloquear a tentativa de derrubada dos vetos.

\section{Considerações Finais}

A literatura sobre os governos estaduais no Brasil tem crescido nos últimos anos, porém ainda apresenta algumas fronteiras pouco exploradas. Dentre elas, está a comparação entre diversos estados que tem sido enfrentada por alguns trabalhos (Tomio e Ricci, 2012) e o estudo de governos mais antigos. Neste artigo, buscou-se apresentar o padrão da produção legislativa e da relação entre o Executivo e o Legislativo durante o primeiro governo Brizola (1983-1987), o primeiro governo estadual democrático do Estado do Rio de Janeiro desde a fusão com o Estado da Guanabara.

A teoria sobre governadores desenvolvida por Abrucio (1998), apesar de considerar o período analisado aqui como o início do que seria o "ultrapresidencialismo estadual", consolidado no momento pós-Constituição, estabeleceu hipóteses para a relação ExecutivoLegislativo a serem testadas também para o governo Brizola. O governo Brizola foi capaz de, em sua maior parte, aprovar as propostas que enviou para a Assembleia, o que ficou claro pela sua taxa de sucesso. A tarefa de aprovar suas mensagens foi fortemente facilitada pela conjunção de um mecanismo de pedido de urgência que continha a possibilidade de aprovação automática e a estratégia de fazer uso desse mecanismo em um período transitório, de pouca presença dos deputados estaduais em plenário. As aprovações, em grande parte da agenda legislativa proposta,

\footnotetext{
${ }^{20} \S 4$ do artigo 144 da Constituição Estadual de 1975 (Rio de Janeiro, 1975).
} 
não significaram dominância do Executivo sobre a produção legislativa. Os dados mostram que o Legislativo teve maior número de autoria nas leis aprovadas. Essa dominância foi diminuída pelo fato de grande parte desta produção da Assembleia ser de leis de pouco alcance e de pouca importância. Todavia, a larga produção de leis de declaração de utilidade pública e de caráter honorífico não pode obscurecer a aprovação, pela Assembleia, de uma agenda social e administrativa também forte. $\mathrm{O}$ fato de o Executivo ter uma agenda legitimada eleitoralmente e a capacidade de aprová-la no Legislativo não significa a existência de um acordo homologatório que estabeleça a omissão da Assembleia em assuntos importantes. Descontadas as leis de declaração de utilidade pública e de caráter honorífico da produção do Legislativo, percebe-se uma divisão mais paritária da agenda relevante.

A existência de uma agenda importante levada à frente pelos deputados estaduais não significou, todavia, total capacidade para implementá-la. Os dados referentes aos vetos apostos pelo governador mostram que o número deles esteve longe de ser residual. No entanto, a aposição de vetos pelo governador foi pouco desafiada pelos legisladores no período analisado, com apenas quatro destes sendo derrubados de um total de 143. A discrepância entre os números apresentados aqui e os apresentados para períodos mais recentes (Graça, 2012) mostra que os deputados estaduais fluminenses conseguiram construir maior capacidade de resistir aos vetos governamentais depois da diminuição da quantidade de votos necessária para a derrubada de vetos.

A produção legislativa tanto do Executivo quanto do Legislativo no período do governo Brizola não destoa fortemente do período mais recente. Este dado coloca em perspectiva a afirmação de Tomio e Ricci (2012) de que a força dos governadores também tem origem na limitação do escopo dos Poderes Legislativos estaduais pelo caráter concorrente de sua área de atuação definida na Constituição de 1988. Os dados mostram que, mesmo antes de 1988, a agenda do Legislativo, pelo menos no Estado do Rio de Janeiro, era composta em grande parte por leis de impacto nulo ou limitado. Isto, se encontrado em outros estudos similares, levantaria a hipótese de que o pouco espaço de atuação dos deputados estaduais, argumentado como uma restrição posterior à Constituição de 1988, possa ser a continuação de uma estrutura federal já determinada no período anterior à Constituinte. 
No período analisado aqui, além da força simbólica de uma figura opositora ao regime militar assumir mandato eletivo executivo no estado pela primeira vez em 17 anos, contou a favor do governador o fato de ele estar sob a regra da Constituição Estadual de 1975. Embora o próprio Brizola a tenha criticado em seu discurso de posse, o fato é que aquela Constituição tornava muito difícil para a ALERJ derrubar os vetos do governador e permitia a ele comandar a agenda relevante. Porém, mesmo embasado em uma Constituição de caráter autoritário, portador de um imenso capital simbólico e líder do maior partido da Assembleia, o governo Brizola não conseguiu "rotinizar" a relação carismática que o levou ao cargo, impondo no seu trato com a ALERJ um caráter mais programático como desejava, e precisou recorrer a uma coalizão com o PTB e o PMDB, partido que combateu fortemente nas eleições por suas práticas clientelistas, para melhorar a governabilidade de seu mandato.

\section{Referências Bibliográficas}

ABRUCIO, F. L. Os Barões da Federação: os governadores e a redemocratização brasileira. São Paulo: Hucitec/USP, 1998.

.; TEIXEIRA, M. C. A.; e COSTA, V. M. F. O Papel Institucional da Assembleia Legislativa paulista: 1995-1998. In: SANTOS, F. (org.), O Poder Legislativo nos Estados: Diversidade e Convergência. Rio de Janeiro: Ed. FGV, 2001. pp. 219-246.

BRASIL. LEI $\mathrm{N}^{\mathrm{o}}$ 6.339, DE $1^{\circ}$ DE JULHO DE 1976. Disponível em: <http://www.planalto.gov.br/ccivil_03/leis/1970-1979/L6339.htm> . Data de Acesso: 01/06/2013.

BRASIL. LEI No 6.978, DE 19 DE JANEIRO DE 1982. Disponível em: <http://www.planalto.gov.br/ccivil_03/leis/1980-1988/L6978.htm> . Data de Acesso: 01/06/2013.

BRASIL; TSE. Candidatos Eleitos: Período de 1945 a 1990. TSE, 2013. Disponível em: <http://estatistica.tse.jus.br:7777/dwtse/f? $\mathrm{p}=1945: 1: 2232181138530351>$. Data de Acesso: 01/06/2013. 
CERVI, Emerson Urizzi. Produção legislativa e conexão eleitoral na assembléia legislativa do estado do Paraná. Revista de Sociologia e Política, Curitiba, vol. 17, n. 32, pp. 159-177, fev. 2009.

DINIZ, Eli. Voto e Máquina Política: Patronagem e Clientelismo no Rio de Janeiro. Rio de Janeiro: Ed. Paz e Terra, 1982. 228p.

DOMINGUES, M. P. Espírito Santo: Produção Legal e Relações entre os Poderes Executivo e Legislativo entre 1995 e 1998. In: SANTOS, F. (org.), O Poder Legislativo nos Estados: Diversidade e Convergência. Rio de Janeiro: Ed. FGV, 2001. pp. 85-112.

EATON, Kent. Politics Beyond the Capital: The Design of Subnational Institutions in South America. Stanford, California: Stanford University Press, 2004.

FIGUEIREDO, Argelina e LIMONGI, Fernando. Executivo e Legislativo na Nova Ordem Constitucional. Rio de Janeiro: Ed. FGV, 1999.

GRAÇA, Luís Felipe G. Produção legislativa e Vetos no Estado do Rio de Janeiro (2003-2010). In: $8^{\circ}$ ENCONTRO DA ASSOCIAÇÃO BRASILEIRA DE CIÊNCIA POLÍTICA. Gramado, RS, 2012.

GROHMANN, L. G. M. O Processo Legislativo no Rio Grande do Sul: 1995 a 1998. In: SANTOS, F. (org.), O Poder Legislativo nos Estados: Diversidade e Convergência. Rio de Janeiro: Ed. FGV, 2001. pp. 113-162.

LAPINSKI, John S. Policy Substance and Performance in American Lawmaking, 1877-1994. American Journal of Political Science, vol. 52, n. 2, pp. 235-251, 2008.

LOPEZ, Felix G. O poder legislativo e o preenchimento dos cargos na Secretaria Estadual de Educação e Secretaria Estadual de Saúde do Rio de Janeiro (1999-2006). In: XXXII ENCONTRO ANUAL DA ANPOCS. Caxambu, 2008.

PEREIRA, Ricardo P. Sob a ótica da delegação: Governadores e Assembléias no Brasil Pós1989. In: SANTOS, Fabiano (Org.). O Poder Legislativo nos Estados: Diversidade e Convergência. Ed. FGV, 2001. pp. 245- 287. 
RICCI, Paolo. O conteúdo da produção legislativa brasileira: leis nacionais ou políticas paroquiais?. DADOS - Revista de Ciências Sociais, Rio de Janeiro, Vol. 46, n. 4, pp. 699734, 2003.

RIO DE JANEIRO. Constituição do Estado do Rio de Janeiro. 1975

RIO DE JANEIRO. Discurso de posse de Lionel Brizola. Diário Oficial do Poder Legislativo do Estado do Rio de Janeiro. Data: 16 de março de 1983. Rio de Janeiro. Mar. 1983a.

RIO DE JANEIRO. Seis meses de governo Democrático e Popular. Diário Oficial do Poder Legislativo do Estado do Rio de Janeiro. Data: 23 de Setembro de 1983. Rio de Janeiro. Set. $1983 b$.

SAMUELS, David e ABRUCIO, Fernando. Federalism and Democratic Transitions: The "New" Politics of the Governors in Brazil. Publius: The journal of Federalism vol. 30, n. 2, Spring, 2000.

SANTOS, Fabiano. A Dinâmica Legislativa no Estado do Rio de Janeiro: Análise de uma Legislatura. In: SANTOS, Fabiano (Org.). O Poder Legislativo nos Estados: Diversidade e Convergência. Ed. FGV, 2001. pp.163-187.

. e AMORIM NETO, O. O Segredo Ineficiente revisto: O que propõem e o que aprovam os deputados brasileiros. DADOS-Revista de Ciências Sociais, Rio de Janeiro, vol. 46, n. 4, pp. 661-698, 2003.

SARMENTO, Carlos Eduardo. Entre o carisma e a rotina: as eleições de 1982 e o primeiro governo. In: FERREIRA, Marieta Morares (Org). A força do povo: Brizola e o Rio de Janeiro. Rio de Janeiro: ALERJ, CPDOC/FGV, 2008. pp. 43-67.

SENTO-SÉ, João Trajano. As várias cores do socialismo moreno. Anos 90, Porto Alegre, vol. 11, n. 19/20, op.49-76, jan./dez. 2004.

SOUZA, Amaury de; LIMA JUNIOR, Olavo Brasil e FIGUEIREDO, Marcus. Brizola y las elecciones de 1982 en Río de Janeiro. Revista Mexicana de Sociología, vol. 49, n. 2 (Apr. Jun.), pp. 233-281, 1987. 
SOUZA, Cíntia. A Evolução da Regulação do Financiamento de Campanha no Brasil (19452006). Dissertação (Mestrado em Ciência Política), Instituto Universitário de Pesquisas do Rio de Janeiro. Rio de Janeiro, 2010. 104 p.

TALARICO, José. Depoimento ao CPDOC (Conversando sobre Política). Org. Américo Freire. Rio de Janeiro: Ed. FGV, 1998.

TOMIO, Fabricio. A criação de municípios após a Constituição de 1988. Revista Brasileira de Ciências Sociais, vol. 17, n. 48, pp. 61- 89, 2002.

TOMIO, Fabricio. Federalismo, Municípios e Decisões Legislativas: A criação de Municípios no Rio Grande do Sul. Revista de Sociologia Política, Curitiba, n. 24, pp. 123-148, 2005.

TOMIO, Fabricio e RICCI, Paolo. O Governo Estadual na Experiência Política Brasileira: Os desempenhos legislativos das Assembleias Estaduais. Revista de Sociologia e Política, Curitiba, vol. 21, n. 41, pp.193-217, fev. 2012. 